\title{
The Influence Of Kalium Cromate Inhibitor \\ On Corrosion And Fatique Crack Growth Of Aluminium Alloy 2024-T3 In The Sea Water Environment
}

\author{
Waris Wibowo $^{1 *}$, Mochammad Noer Ilman ${ }^{2}$ \\ 1) Akademi Maritim Yogyakarta, Jl. Magelang KM 4.4, Yogyakarta 55284, Indonesia \\ ${ }^{2)}$ Jurusan Teknik Mesin dan Industri, Fak. Teknik Universitas Gadjah Mada, Jl. Grafika \\ No.2 Yogyakarta 55281 \\ * Corresponding Author. Email: waris.amy68 @ gmail.com. Telp. +628174110019
}

\begin{abstract}
Alluminium alloy 2024-T3 is widely used in manufacturing industries such as naval industries due to its relatively good resistance to corrosion. However, alluminium alloy is easily suffered from fatigue corrosion if it is applied in corrosive environment such as sea water. One of the methods to control the corrosion is applying inhibitor. This research aims to study the influence of Kallium Chromate $\left(\mathrm{K}_{2} \mathrm{CrO}_{4}\right)$ inhibitor in reducing the corrosion rates and the fatigue crack growth rates of Al 2024-T3.

In this research, the corrosion rates were tested using three-electrode potential method in the sea water environtment. It was conducted by adding the inhibitor. Whereas, the fatigue crack growth rates were tested using fatigue experiment with the stress rasio $(R)=0,1$ and the frequency of $15 \mathrm{~Hz}$. Corrosion environtment was in the form of sea water which was added by $\mathrm{K}_{2} \mathrm{CrO}_{4}$ inhibitor with the concentration of $0,1 \% ; 0,3 \%$ dan $0,5 \%$.

The findings of the research show that the increase of $\mathrm{K}_{2} \mathrm{CrO}_{4}$ inhibitor concentration tends to reduce continously the corrosion rates, and it achieved the minimum and stagnant condition at the concentration of 0,5\%, the amount of the corrosion rates was $0,0134 \mathrm{~mm} /$ year (38\% reduction). At this condition, for preventing the corrosion fatique rate in the amount of $32,13 \%$.
\end{abstract}

Keywords: alluminium alloy 2024-T3, fatigue corrosion, sea water, inhibitor

\section{INTRODUCTION}

Aluminum $(\mathrm{Al})$ is a material widely used in manufacturing fields since it has some excellence due to its light weight metal, its height on the heat and electrics conductivity, its good machinability nature, its relatively good corossion resistance, and its good castability. Moreover, to increase those characteristics, aluminum should be developed by combining it with the other substances.

One of the aluminum alloys which is widely used in engineering field is aluminum alloy 2024-T3, it is the combination between $\mathrm{Al}-\mathrm{Cu}$ and copper in the average of 3,8-4,9\% whereas $\mathrm{T} 3$ is the heat treatment processes which consist of immersing into solid solution, quenching and aging in order to reach the intended hardness level (Polmear, 1981). This aluminum alloy is usually used for producing machinary components such as shafts dan gears, bolts dan nuts, couplings, fuse 
parts, hydraulic valve bodies, and pistons, (asm.matweb.com). However, Aluminum alloy 2024-T3 is susceptible toward corrosion and fatique growth rate if it is applied in the environment which has the corrosive characteristic, like sea water environment.

According to Davis (2000) the control upon the corrosion can be conducted by the method of material selecting, coating, inhibitor using, and designing. One of the controlling methods is using the inhibitor to prevent the corrosion attack and fatique crack growth rate on Al 2024-T3. Generally, corrosion inhibitor is a chemical substance and when it is added into a certain environment it can reduce the corrosion attack rate of the metal. Based on that phenomenon, it can be said that the discussions on the roles of inhibitors are still urgently needed.

This reseach is aimed to study the effectiveness influence of kalium cromate inhibitor $\left(\mathrm{K}_{2} \mathrm{CrO}_{4}\right)$ in increasing the corrosion resistance and fatique crack growth rate on aluminum alloy $\mathrm{Al} 2024-\mathrm{T} 3$ in the sea water environment.

The fatique failure on the structure caused by dinamic load and begun with the form of prelimanary crack continued by crack growth and finally the structure faces the fracture. The first location of the crack is the location which has a minimum strength and at the same time has a maximum stress, so that in order to predict the fatique live of the metal is quite difficult bacause there are many influenced factors, whereas corrosion fatique is a corrosion caused by the existance of crack growth which occurs as a result of the combination between corrosion and the fluctuated stress or cycles. Related to that matter there are several studies discussing those phenomena.

Sanyoto, et.al (2008) studied the crack growth rate occured on the flat of aluminum alloy 2024-T3 with the uniaxial fatique load, where there were opened holes with constant diameters and the distances between the holes were different. The findings of the research showed that the distances of the small holes caused the heavy stress distributions, so that the fatique growth rate would be more rapid. Furthermore, it was also stated that the bigger the ratio of the load (R) then the curve $(\mathrm{da} / \mathrm{dN})-(\Delta \mathrm{K})$ would swift more to the left, and at the same stress intensity factor $(\Delta \mathrm{K})$ then the crack growth rate $(\mathrm{da} / \mathrm{dN})$ would increase at the heavy load ratio(R).

The comparison study had been conducted on fatique crack growth rate occuring to $\mathrm{Al}$ 6013-T6, alclad Al 2024-T3, and $\mathrm{Al}$ 2024-T3 in the environment of $3,5 \%$ of aeration water salt, using metalography method, fractography, and fatique corrosion (Chaudhuri, et.al, 1992). The findings indicated that the defence of the fatique corrosion of Alclad Al 2024-T3 was the best, it happened because clad coating provided the corrosion defence protection to the basic metal of $\mathrm{Al}$ 2024T3.

Tu, et.al. (1991) studied the fatique corrosion comparison behavior between the anodized and unanodized $\mathrm{Al} 2024-\mathrm{T} 3$ in the environment of 3,5\% of $\mathrm{NaCl}$. The result of the study show that $E_{c o r}$ of the anodized condition faced the decrease gradually in the beginning of the fatique corossion and rapidly when approaching the cracking. Moreover, $E_{c o r}$ in the unanodized environment did not change too much in the low frequency fatique corrosion condition but on the other hand it would decrease rapidly when the frequency is high. 
The study had been done by (Wan, et.al., 2000) on the relationship between the length of the crack, load ratio $(\mathrm{R})$, and the corrosion environment in the solution of $0,5 \mathrm{M} \mathrm{NaCl}$ toward $\mathrm{Al} 2024-\mathrm{T} 3$. The findings showed that the fatique crack growth rate would be rapidly occured on the short crack and on low level of load ratio. Whereas the concentration of oxygen would influence to fatique crack growth rate, both for the short and the long crack as a result of the hydrogen brittling.

The research on the corrosion of aluminum Al 2024-T3 had been conducted by (Ilman, et.al. ,2009). The findings indicated that the corrosion rate between Icorr $144,91 \mu \mathrm{A} / \mathrm{cm}^{2}$ was equivalent with the corrosion rate of 0,649 mpy or 0,0165 $\mathrm{mm} / \mathrm{year}$ and the potencial range was $-400 \mathrm{mV}$ up to $-750 \mathrm{mV}$.

The study on local corrosion to Al 2024-T3 in $\mathrm{NaCl}$ solution using intermittent method had been done by (Harsito, 2000). The findings indicated that $\mathrm{NaCl}$ solution with the concentration of 3,5\%-0,0035\% caused the pitting corrosion, whereas in $\mathrm{NaCl}$ solution with the concentration of $0,0035 \%$, the chlorida ion in this solution caused the uniform corrosion.

\section{METHOD}

\section{Composition Testing}

Composition testing was conducted to identify the composition and the characteristics of the material namely the aluminum alloy Al 2024-T3 used in the research. The data of the materials composition was using the data taken from the previous research conducted by (Ilman, 2009).

\section{Hardness Testing}

Hardness testing was conducted to recognize the hardness of the specimen of aluminum alloy Al 2024-T3. The equipment which was used to test the hardness was Buehler microhardness tester with vickers method. The position of the testing was surface direction in transversal and longitudinal position.

\section{Tensile Strength Testing}

Tensile strength testing was done to identify the previous strength of aluminum alloy Al 2024-T3, so the mechanical characteristics of the tested material could be obtained. Those mechanical characteristics are for example: the elastic limit, the yield strength and the tensile strength. Tensile strength testing in this research had been conducted in accordance with the material rolling, and the specimen was made in accordance with the standarded JIS Z2201 non ferrous number 6.

\section{Micro Characterization and Macro Structure Testing}

The Micro characterization and macro structure testing on aluminum $\mathrm{Al}$ 2024-T3 would be done by doing the micro photo on the corroded areas. To recognize the form of the micro characterization and the macro structure of the specimen, it was done by observing the direction of the surface, transversally and longitudinally. The next step was polishing and etching by means of Keller's reagent solution with the composition of $1 \mathrm{ml} \mathrm{HF}+1,5 \mathrm{ml} \mathrm{HCl}+2,5 \mathrm{ml} \mathrm{HNO} 3$ and $95 \mathrm{ml} \mathrm{H} 2 \mathrm{O}$. The observation on the micro and macro structure was done using optic 
microscope with a certain zoom on the objective lens until the optimum results were obtained.

\section{Corrosion Rate Testing}

The electrochemical testing was done using the saturated calomel electrode (SCE) as the main electrode where as the auxiliary electrode used is platinum. The corrosion testing was done in the pure sea water environment and in the sea water environment added with inhibitor of kalium cromate $(\mathrm{K} 2 \mathrm{CrO} 4)$ with the concentration variation of $0,1 \% ; 0,3 \%$, and $0,5 \%$ and the $\mathrm{pH}$ of sea water was 7.64 .

\section{Fatique Crack Growth Rate Testing}

The specimen for fatique crack growth rate testing was prepared in accordance with the standard from ASTM E-647. The specimen with Center Cracked Tension (CCT) was selected based on the previous crack which was located in the middle of the flat. The fatique experiment was conducted using servohydraulics machinary testing, sinusoidal load was selected, stress ratio was $\mathrm{R}=\mathrm{Smin} / \mathrm{Smax}=0,1$ and the frequency was $15 \mathrm{~Hz}$. The stress level used was $20 \%$. The previous crack was made upright toward the rolling direction. Whereas, in order to ease the observation, the chamber material was made of transparent acrylic resin.

\section{SEM dan EDX testing}

Scanning Electron Microscope (SEM) testing was used to observe the difference of the micro structure from the result of the research on the corrosion rate as follows: (a) potencial sel of three electrodes, (b) submersion for 24 hours, and (c) fatique crack growth. The implementation of those three behaviors were chosen from the result of the most optimum corrosion toward the influence of the inhibitor adding of kalium cromate $(\mathrm{K} 2 \mathrm{CrO} 4)$ in the sea water environment on aluminum alloy Al 2024-T3. In order to identify the chemical composition of the corrosion product and the main metal after it was corroded then the Energy Dispersive X-Rays Spectroscopy (EDX) testing was conducted.

\section{FINDINGS AND DISCUSSIONS}

\section{Material Characterization}

The composition of the materials had been studied by the other researcher (Ilman, 2009) and the standard comparison of composition from those materials. The result of the composition testing indicated that the specimen under studied had a composition which belonged to the standard limitation of the material composition of Al 2024-T3 (asm.matweb.com, 2011).

The micro stucture testing was conducted to recognize the metallurgy of the surface of the material so that the mechanical nature can be identified. It was done using the optic microscope. From the result of the observation on the micro structure of the specimen Al 2024-T3, it showed that the micro structure of the surface was in equiaxed whereas the transversal and longitudinal levels had stretching grain which was parallel with the rolling direction or it was called texture. 
The characterization of the micro structure (microanalysis) of Al 2024-T3 was done on the longitudinal level using Scanning Electron Microscope (SEM) method and combined with Energy Dispersive X-Rays Spectroscopy (EDX). The result of the SEM observation indicated that the second grain phase was in dark color in the form of inklusi oxide or precipitate. The result of EDX testing showed that the main metal contained $\mathrm{Al}$ of $91,37 \%$ and $\mathrm{Cu}$ of $5,02 \%$. The result of the EDX testing on the precipitate of the metal indicated that the main contents of the main presipitate were $(2: 1)$. It contained of aluminum (Al) of $57,21 \%$ and copper $(\mathrm{Cu})$ of $28,40 \%$.

The hardness testing using Vickers method on Al 2024-T3 was taken from the following levels : on the surface, transversal and longitudinal levels. The result indicated that the surface and the transversal levels had the higher hardness if it was compared with the hardness of the melintang direction. The result of the tensile strength testing indicated that the maximum tensile strength $(\sigma \mathrm{T})$, yield strength $(\sigma y)$ and elongation of the material were still on the material standard limitation of Al 2024-T3, it almost approached the ASM standard in Handbook vol. 2.

\section{Analysis Corrosion in the Sea Water Environment}

The corrosion rate testing with the potencial sel of three electrodes was based on the Tafel extrapolation method, in the sea water environment without the inhibitor, it showed that ther corrosion rate was $0,0216 \mathrm{~mm} / \mathrm{year}$, whereas the best influence of kalium cromate inhibitor was on the concentration of $0,5 \%$ with the corrosion rate of $0,0134 \mathrm{~mm} /$ year or it can be said that there was a decrease of about $38 \%$. The form of the corrosion on $\mathrm{Al} 2024-\mathrm{T} 3$ in the pure sea water medium and in the sea water added with inhibitor tended to be a pitting corrosion and uniform corrosion. Kalium Cromate inhibitor (K2CrO4) could prevent the corrosion by oxidizing so that it yielded the passive film which could close the surface of Al 2024-T3 which was easily corroded.

\section{The Analysis on the Corrosion Fatiques Crack Growth}

Based on the research on the fatique crack growth rate in the environments of atmosphere, pure sea water and sea water which was added with kalium cromate inhibitor in the concentration of $0,1 \% ; 0,3 \%$ dan $0,5 \%$, they indicated that the age of the crack on Al 2024-T3 in the air environment was about 154572 cycles, in the pure sea water environment was 99807 cycles, and the added of kalium cromate inhibitor in concentration of $0,1 \%$ was 108275 cycles, in concentration of $0,3 \%$ was 118296 cycles and in concentration of $0,5 \%$ was 131873 cycles. The numbers of the lowest cycles of the testings on fatique crack growth in the five different environments indicated that the water environment had the lowest cycles numbers. It was proven that the sea water environment with $\mathrm{pH} 7,64$ had the tendency as a corrosive medium.

\section{Inhibitor Efficiency}

Kalium cromate is an anodic inhibitor which oxidizes and it will protect the aluminum in a passive condition from the damage of the passive film of Al 2024T3 surface. Beside that the cromate will act as a catodic inhibitor which will speed the reaction on the catodic as a catalisator that will make the hydrogen lost. 
Inhibitor corrosion was measured using its efficiency, namely by comparing the corrosion rate from the reviewed system. The result of the testing on the potencial sel of three electrodes and testing on the corrosion fatique indicated that the influence of the inhibitors was getting more increase as the increase of the inhibitor concentrations. In the inhibitor with the concentration of $0,5 \% \mathrm{~K} 2 \mathrm{CrO} 4$, it could resist the corrosion rate of $38 \%$ for the testing conducted with the potencial sel of three electrodes, whereas the testing on the corrosion fatique of three electrodes indicated that the decrease of the corrosion rate was $32,13 \%$.

\section{CONCLUSIONS}

\section{Conclusions}

a. The corrosion rate of aluminum alloy Al 2024-T3 in the sea water was $0,0216 \mathrm{~mm} /$ year. The existence of Kalium Cromate inhibitor would decrease the corrosion rate in the amount of $0,0134 \mathrm{~mm} / \mathrm{year}$ (the decrease was $38 \%$ ) in the $\mathrm{K}_{2} \mathrm{CrO}_{4}$ concentration of $0,5 \%$.

b. The inhibitor testing on the corrosion fatique rate of Al 2024-T3 with kalium cromate inhibitor had the tendency that the protection trend toward corrosion fatique and the inhibitor efficiency would increase along with the increase of the kalium cromate concentration, where the best concentration of $\mathrm{K}_{2} \mathrm{CrO}_{4}$ was $0,5 \%$ for preventing the corrosion fatique rate in the amount of $32,13 \%$.

\section{Suggestions}

a. The follow-up research can be conducted using the variation of the inhibitors and the higher concentration in order to identify the maximum limitation of the inhibitors.

b. In order to obtain the lower corrosion rate, it is needed to combine the inhibitor with the low concentration of the inhibitors.

\section{BIBLIOGRAPHY}

ASM Handbook, 1990, "Properties and selection: Non Ferrous Alloy and Special Propuse-Materials”, Metal Handbook, vol. 2

ASTM, 2003, "Metal test Methods And Anlitycal Procedurs", Annual Book of ASTM Standard, sc.3 Vol 03.01, E647-00, pp.615-657, Bar Harbor Drive, Weat Conshohocken.

Chaudhuri, Y.M. Tan, K.Patni, and A. Eftekhari., 1992," Comparison of Corrosion Fatigue Properties of 6013 Bare, Alclad 2024, and 2024 bare Aluminium Alloy Sheet Materials", Journal of Material Engineering and Performance (JMEPEG) 1. pp. 91-96

Davis,J.R., 2000,"Corrosion Understanding The basics",ASM International, All Rights Reserved, Printed in the United States of America

Harsito, 2000,"Uji Korosi Lokal pada Al 2024-T3 dalam Larutan NaCl dengan Metoda Intermitten", Korosi, Volume 11, No.1, pp. 14-21

Ilman, Yustiasih P., Triono., 2009, "Corrosion Fatigue Crack Growth Rate Behaviour of Al2024-T3 in Seawater Environment" 
JIS, 1973,” Non Ferrous Metal “, Japanese International Standar, pp.36

Polmear,I.J.,1981, "Light Alloy”, $3^{\text {th }}$ edtion Arnold, London

Sanyoto BL, Wajan Berata., 2008, “ Laju Perambatan Retak Plat Aluminium 2024T3 dengan Beban Fatigue Uniaksial pada Rasio Beban dan Jarak Diameter Lubang Berbeda", Jurnal Ilmiah Teknik Mesin CAKRAM Vol.2 No. 2 ITS, pp.82-91

Tu.G.C, Hwang.R.Y, Chen,I.T., 1991," A Study of Corrosion Fatigue Behaviour of Aodized and Unanodized 2024-T3 Aluminium Alloy ", Journal of Materials Science, National Chiao Tung University, Taiwan.

Wan, G.S. Chen, M. Gao, R.P. Wei., 2000," Interactions Between Mechanical and Environmental Variables for Short Fatigue Cracks in a 2024-T3 Aluminium Alloy In 0,5 M NaCl Solutions ", Journal Metallurgical and Materials Transactions, Vol 31A, pp.1025-1033

http://asm.matweb.com/search/SpecificMaterial.asp?bassnum=MA2024T3 